\title{
Learning Styles of Male and Female Students of Nepal
}

\author{
Amrit Kumar Rai ${ }^{1}$ \& Megha Raj Dhakal ${ }^{2}$ \\ ${ }^{1} \mathrm{PhD}$ Scholar, Mewar University, Rajasthan, India. \\ ${ }^{2}$ Associate Professor, Nobel College, Pokhara University, Nepal.
}

\section{Corresponding Author}

Amrit Kumar Rai

Email: amritraisj@yahoo.com

\begin{abstract}
Learning is natural phenomena starts with the birth; it is a gradual process of investigation of new knowledge. Every creature has their own learning styles as their biological and social nature. People have superior power to learn many things as they become interested. School is one platform to learn many things for the students. School creates the learning environment but learning style may be varied in student to student. The study aims to identify the learning styles of male and female students of public and private school of Nepal. Primary data were collected from Makwanpur, Chitwan, Gorkha and Dhading Districts among Chepang Community. The study is done among the 368 students of four districts. The three types of learning styles: Visual, Auditory, and Kinesthetic (VAK) model developed by Neil Fleming was used in field for data collection. The result shows that there is no significant different between male and female students regarding their learning styles. It indicates that achievement and performance of male and female is similar. In Nepalese society, there are some gender differences in social relationship. Still, in most of the society, daughters are given less priority for their growth and development because of the patriarchal concept of society but the study has given the different result than the general concept. It is shown that a daughter can give better result if she will get better learning environment. The result has challenged the discriminatory gender relation in society.
\end{abstract}

\section{KEYWORDS}

Auditory, Kinesthetic, Learning, Visual

\section{INTRODUCTION}


When we talk about the male and female then automatically it creates the concept of gender relation. Natural phenomena and socio-cultural life is made because of the gender relation. There is inevitable relationship between the male and female though biologically there is some difference in male and female. Similarly, social norms and values are associated with gender relation that may effect on the learning and achievement of people. Family is the primary school for learning. Children learn many things from family, community and school. The learning styles of students may
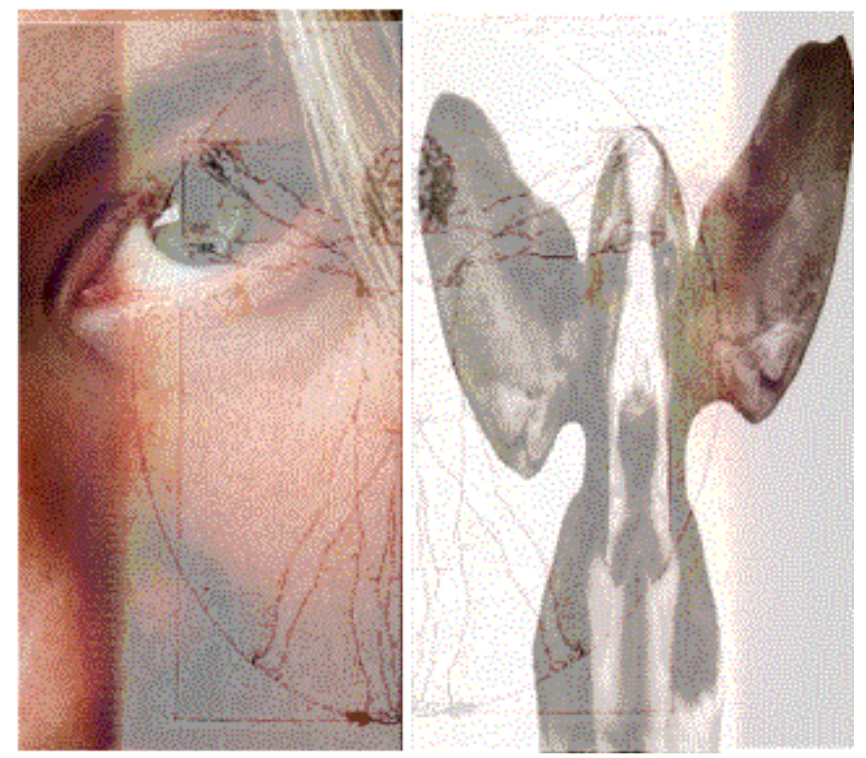
be varied by nature and intelligence of students. Student learns many things from the teaching of teachers, family, reference materials, peers and school environment. Learning is the source of interaction with surrounding phenomena. Various scholars like Dunn and Dunn (1987, p. 89), Claxton and Ralston (1978), Keefe (1979) Clenton (2015) and (Grifths, 2008; Grenfell \& Harris, 1999) have defined learning styles in various ways. The definition of learning styles is a major concern of teachers and scholars in the field of education because it is directly associated with the performance of

Figure 1: Visual, Auditory, Kinesthetic (VAK) model by Fleming's (2001). teachers and achievement of students. In relation to the learning style, Claxton and Ralston (1978) said that consistent way of responding and using stimuli in the context of learning (p. 7). Similarly, for Keefe (1979) learning styles are the cognitive, affective and physiological traits that indicates the way of learners' perceive, interact with, and respond to the learning environment (p. 4). Learning is critically important for the better improvement of educational sectors (Grifths, 2008; Grenfell \& Harris, 1999). Learning is one psychological process which talks about learners' perception towards their phenomena and how they interact with those phenomena will determine the learning intelligence. There are different theories of learning. The number of researchers have discussed with the learning process that structured the learning theories through learning preferences and cognitive style of the individuals (Sadler-Smith, 2001; Bailey, Onwuegbuzie, \& E., 2000; Busato, Prins, Elshout, \& C., 2000; Hsu, 1999) (Sadler-Smith, 2001; Busato, Prins, Elshout, \& C., 2000; Hsu, 1999).

Scientifically, there are different types of model for learning styles as developed by the educationists. The study has adopted the learning style of Neil Fleming to identify the learning style of student. The learning style of Fleming's (2001) which consists the Visual, Auditory, Kinesthetic (VAK) model (Figure 1) is very common and widely used model. The VAK learning style uses the three main sensory receivers: Visual, Auditory and Kinesthetic (movement) to determine the dominant learning style. Learners are interested to use this model 
to receive and learn new information and experiences. Different students have different interest of learning ways; either they learn by using the visual or by auditory or kinesthetic technique. Mostly, one or two of these receiving styles is normally dominant. One can practice different style in different types of issue of learning.

According to the VAK theorists, there is need to present the information by using all three styles of learning which allows opportunity to all learners to become involved in all types of learning style so it will be easy to know their preferred style (Rourke, Ahmed, Collins, Hayman-Abello, \& Warriner, 2002). The study had also given the option of all three styles while asking the question to students during the survey. The students had chance to chose only one styles what they preferred most. Learning depends on various independent factors. Social characteristic of male and female is different which may effect in their learning style also. On the other hand, learning attitude and school environment may effect in learning of male and female students so the study has measured the learning style of male and female of public and private school of Nepal.

\section{MATERIALS AND METHOD}

The study was conducted in the Makwanpur, Chitwan, Gorkha and Dhading Districts among the 368 student when $41 \%$ taken from public and 59\% taken from the private school. The students were selected purposively who were from the Chepang community. Chepang is one of the disadvantaged ethnic communities. Economically, Chepang are more vulnerable and have food security problem among the majority household which may effect on their education. The study is based on the descriptive and exploratory research design. It has identified the existing status of educational status as well as it also explored the relationship between the male and female students regarding their learning style. The structured questionnaire survey was done to collect the opinion of students. The standard scale developed by Neil Fleming: Visual, Auditory, Kinesthetic (VAK) model was used for survey. The statistical model: cross tab, Chi-Square and independent sample t-test was done to analyze the data. The sample size of this study is done among the 368 students. The sample size is calculated by using the standard sample calculation formula of 95\% confidence level and 5\% margin of error. The data was collected from the four districts where Chepang communities are staying since long time with higher population than the other districts. As well as there is some provision of scholarship also for the Chepang children to enroll in school.

\section{RESULTS AND DISCUSSION}

The study has presented the data of male and female students about their learning style. Learning as an internal process that is different for every individual and learning style can be described as the way individuals acquire new information. Fox and Bartholomae (1999) describe learning styles as a biological and personal demographical characteristic, which is defined by the way 
individual process information. Each learner has her/his preferred ways of perception, organization and retention that are unique and reliable (Hsu, 1999; Chou \& Wang, 2000). Learning processes support to understand the individual differences of one student. Naturally it is well known and acceptable that different people have different ways of learning. As the nature and interest of people, some types of learning experience suit one person better than others (Bailey, Onwuegbuzie, \& E., 2000; Sadler-Smith, 2001; Kolb, 1999). The same things can be differently defined as the perception and experience of individual. Male and female may have different opinion and perception towards the source of knowledge and surrounding environment which may have effect on their learning style and attitude so the study analyzed their learning style as below:

\section{Learning styles of male and female students}

Three main sensory receivers in learning styles are visual, auditory and kinesthetic. Learners use all three modalities to receive and learn new information and experiences. Most learners possess a dominant or preferred learning style. However, some learners have a mixed and evenly balanced blend of these three styles. As the objective of this study, learning styles of male and female students of selected school was analyzed and identified the different between them. The Table 1 explores the results of surveyed data on learning styles of high school Chepang students from study area with reference to gender.

Table1: Learning styles of male and female students $(\mathrm{N}=368)$.

\begin{tabular}{|c|c|c|c|c|}
\hline & & \multicolumn{2}{|l|}{ Gender } & \multirow{2}{*}{$\begin{array}{l}\text { Pearson } \\
\text { Chi-Square }(\mathrm{P})\end{array}$} \\
\hline & & Male $(\%)$ & Female (\%) & \\
\hline \multirow{3}{*}{$\begin{array}{l}\text { When operating new } \\
\text { equipment for the first } \\
\text { time }\end{array}$} & Visual & 14.3 & 16.8 & \multirow[t]{3}{*}{0.295} \\
\hline & Auditory & 25.3 & 33.5 & \\
\hline & Kinesthetic & 5.8 & 4.4 & \\
\hline \multirow{3}{*}{$\begin{array}{l}\text { When seeking travel } \\
\text { directions }\end{array}$} & Visual & 21.3 & 19.9 & \multirow[t]{3}{*}{0.090} \\
\hline & Auditory & 19.9 & 30.3 & \\
\hline & Kinesthetic & 3.8 & 4.6 & \\
\hline \multirow[b]{3}{*}{ Cooking new dish } & Visual & 26.4 & 29.9 & \multirow[t]{3}{*}{0.231} \\
\hline & Auditory & 6.6 & 5.8 & \\
\hline & Kinesthetic & 12.4 & 19 & \\
\hline \multirow{3}{*}{$\begin{array}{l}\text { To teach someone } \\
\text { something }\end{array}$} & Visual & 12.2 & 12.7 & \multirow[t]{3}{*}{0.355} \\
\hline & Auditory & 13 & 13.8 & \\
\hline & Kinesthetic & 19.9 & 28.5 & \\
\hline \multirow[b]{3}{*}{ Tend to say ... } & Visual & 12.3 & 13.1 & \multirow[t]{3}{*}{0.773} \\
\hline & Auditory & 20.1 & 25.3 & \\
\hline & Kinesthetic & 12.8 & 16.4 & \\
\hline \multirow{3}{*}{$\begin{array}{l}\text { Complaining about faulty } \\
\text { goods }\end{array}$} & Visual & 10.3 & 14.9 & \multirow[t]{3}{*}{0.548} \\
\hline & Auditory & 11.7 & 14.7 & \\
\hline & Kinesthetic & 23.1 & 25.3 & \\
\hline \multirow[b]{2}{*}{ Prefer leisure activities } & Visual & 14.2 & 22.3 & \multirow[t]{2}{*}{0.169} \\
\hline & Auditory & 8.4 & 7.9 & \\
\hline
\end{tabular}


ISSN: 2362-1303 (Paper) | elSSN: 2362-1311(Online)

JOURNAL OF ADVANCED ACADEMIC RESEARCH (JAAR)

April 2017

\begin{tabular}{|c|c|c|c|c|}
\hline & Kinesthetic & 22.3 & 24.8 & \\
\hline \multirow{3}{*}{$\begin{array}{l}\text { Shopping generally I tend } \\
\text { to }\end{array}$} & Visual & 5.2 & 10.7 & \multirow[t]{3}{*}{0.037} \\
\hline & Auditory & 20.8 & 27.3 & \\
\hline & Kinesthetic & 18.9 & 17.2 & \\
\hline \multirow[b]{3}{*}{ Choosing a holiday } & Visual & 23 & 29 & \multirow[t]{3}{*}{0.953} \\
\hline & Auditory & 6.5 & 8.5 & \\
\hline & Kinesthetic & 15.1 & 17.9 & \\
\hline \multirow[b]{3}{*}{ Choosing a new car } & Visual & 23.1 & 27 & \multirow[t]{3}{*}{0.238} \\
\hline & Auditory & 10.1 & 15.8 & \\
\hline & Kinesthetic & 12.4 & 11.5 & \\
\hline \multirow[b]{3}{*}{ learning a new skill } & Visual & 28.1 & 28.1 & \multirow[t]{3}{*}{0.052} \\
\hline & Auditory & 13.1 & 22.7 & \\
\hline & Kinesthetic & 3.8 & 4.1 & \\
\hline \multirow{3}{*}{$\begin{array}{l}\text { Choosing from a } \\
\text { restaurant menu }\end{array}$} & Visual & 13.2 & 17.3 & \multirow[t]{3}{*}{0.914} \\
\hline & Auditory & 11.8 & 14.6 & \\
\hline & Kinesthetic & 19.8 & 23.4 & \\
\hline \multirow[b]{3}{*}{ When listening to a band } & Visual & 9.9 & 11.8 & \multirow[t]{3}{*}{0.154} \\
\hline & Auditory & 31.8 & 41.6 & \\
\hline & Kinesthetic & 3.3 & 1.6 & \\
\hline \multirow[b]{3}{*}{ When concentrating } & Visual & 19.6 & 22.4 & \multirow[t]{3}{*}{0.283} \\
\hline & Auditory & 22.9 & 30.7 & \\
\hline & Kinesthetic & 2.8 & 1.7 & \\
\hline \multirow{3}{*}{$\begin{array}{l}\text { I remember things best } \\
\text { by... }\end{array}$} & Visual & 12.7 & 19 & \multirow[t]{3}{*}{0.200} \\
\hline & Auditory & 9.6 & 8.3 & \\
\hline & Kinesthetic & 22.9 & 27.5 & \\
\hline \multirow[b]{3}{*}{ My first memory is of $\ldots$} & Visual & 14 & 22.1 & \multirow[t]{3}{*}{0.110} \\
\hline & Auditory & 10.1 & 8.4 & \\
\hline & Kinesthetic & 20.2 & 25.2 & \\
\hline \multirow[b]{3}{*}{ When anxious, I ... } & Visual & 18.7 & 28.1 & \multirow[t]{3}{*}{0.269} \\
\hline & Auditory & 20.1 & 20.9 & \\
\hline & Kinesthetic & 5.5 & 6.6 & \\
\hline \multirow{3}{*}{$\begin{array}{l}\text { I feel especially connected } \\
\text { to others because of .. }\end{array}$} & Visual & 4.7 & 7.2 & \multirow[t]{3}{*}{0.417} \\
\hline & Auditory & 11.1 & 10.5 & \\
\hline & Kinesthetic & 29.6 & 36.8 & \\
\hline \multirow{3}{*}{$\begin{array}{l}\text { When I revise for an } \\
\text { exam, I.. }\end{array}$} & Visual & 17.8 & 22.6 & \multirow[t]{3}{*}{0.751} \\
\hline & Auditory & 18.4 & 24.9 & \\
\hline & Kinesthetic & 7.9 & 8.5 & \\
\hline \multirow{3}{*}{$\begin{array}{l}\text { Explaining something to } \\
\text { someone, }\end{array}$} & Visual & 9.8 & 13.4 & \multirow[t]{3}{*}{0.825} \\
\hline & Auditory & 21 & 24.3 & \\
\hline & Kinesthetic & 13.9 & 17.5 & \\
\hline & Visual & $8.50 \%$ & 9.1 & 0.377 \\
\hline Main interests are & Auditory & 32.2 & 42.7 & \\
\hline
\end{tabular}




\begin{tabular}{|c|c|c|c|c|}
\hline & Kinesthetic & 4.1 & 3.3 & \\
\hline \multirow[b]{3}{*}{ Free time is spent... } & Visual & 6.4 & 10.3 & \multirow[t]{3}{*}{0.567} \\
\hline & Auditory & 14.5 & 17 & \\
\hline & Kinesthetic & 23.7 & 28.1 & \\
\hline \multirow[b]{3}{*}{ Contact a new person... } & Visual & 20.8 & 23.7 & \multirow[t]{3}{*}{0.062} \\
\hline & Auditory & 10.4 & 18.3 & \\
\hline & Kinesthetic & 14.1 & 12.7 & \\
\hline \multirow{3}{*}{$\begin{array}{l}\text { I first notice how } \\
\text { people... }\end{array}$} & Visual & 12.1 & 13.8 & \multirow[t]{3}{*}{0.841} \\
\hline & Auditory & 23.9 & 30.3 & \\
\hline & Kinesthetic & 8.4 & 11.5 & \\
\hline \multirow[b]{3}{*}{ If I am very angry... } & Visual & 34.4 & 46.7 & \multirow[t]{3}{*}{0.042} \\
\hline & Auditory & 5.8 & 6.1 & \\
\hline & Kinesthetic & 4.7 & 2.2 & \\
\hline \multirow{3}{*}{$\begin{array}{l}\text { I find it easiest to } \\
\text { remember }\end{array}$} & Visual & 10.2 & 13 & \multirow[t]{3}{*}{0.976} \\
\hline & Auditory & 20.2 & 24.9 & \\
\hline & Kinesthetic & 14.4 & 17.2 & \\
\hline \multirow{3}{*}{$\begin{array}{l}\text { Tell someone is lying } \\
\text { because... }\end{array}$} & Visual & 11.7 & 14.7 & \multirow[t]{3}{*}{0.531} \\
\hline & Auditory & 16.9 & 17.2 & \\
\hline & Kinesthetic & 16.9 & 22.5 & \\
\hline \multirow{3}{*}{$\begin{array}{l}\text { Meeting with an old } \\
\text { friend... }\end{array}$} & Visual & 21 & 37.3 & \multirow[t]{3}{*}{0.000} \\
\hline & Auditory & 4.6 & 4.4 & \\
\hline & Kinesthetic & 19.3 & 13.4 & \\
\hline
\end{tabular}

Source: Field Survey, 2016

To explore learning styles of the high school Chepang students, there were 28 different statements to open up their opinions with reference to three modalities of learning styles: visual, auditory and kinesthetic. The first opinion was "When operating new equipment for the first time I prefer to read the instruction or listen to or ask for an explanation or have a go and learn by trial and error". Out of 364 respondents for this opinion, $14.3 \%$ boys opined visual, $25.3 \%$ opined auditory, $5.8 \%$ opined kinesthetic, and $16.8 \%$ girls stated visual, $33.5 \%$ stated auditory \& $4.4 \%$ stated kinesthetic. In combined data, $31.0 \%$ stated visual, $58.8 \%$ stated auditory and $10.2 \%$ stated kinesthetic. In such cases, many of the students prefer to auditory for an explanation. Second opinion was "When seeking travel direction, I prefer to look at a map, ask for spoken directions or follow my nose / may be use a compass". In this opinion, $21.3 \%, 19.9 \%$ and 3.8\% boys opined on visual, auditory and kinesthetic respectively. On the other hand, $19.9 \%$ girls reported visual, $30.3 \%$ reported auditory and $4.6 \%$ stated kinesthetic. In total, $41.3 \%$ stated visual, $50.3 \%$ stated auditory and $8.5 \%$ stated kinesthetic. In this aspect, they mostly prefer auditory.

The third opinion was "When cooking a new dish, I prefer follow a recipe, call a friend for explanation or follow my instinct / testing as I cook". In this opinion, 26.4\%, $6.6 \%$ and $12.4 \%$ boys stated visual, auditory and kinesthetic respectively. Similarly, $29.9 \%, 5.8 \%$ and $19.0 \%$ girls stated visual, auditory and kinesthetic respectively. In total, $56.3 \%, 12.4 \%$ and 
$31.3 \%$ stated visual, auditory and kinesthetic. In such case, they mostly follow a recipe. The fourth opinion was "To teach someone I prefer to write instruction, explain verbally or demonstrate and let them have a go". The data show that $12.2 \%, 13.0 \%$ and $19.9 \%$ boys stated visual, auditory and kinesthetic respectively. Likewise, $12.7 \%, 13.8 \%$ and $28.5 \%$ girls stated visual, auditory and kinesthetic respectively. In total $24.9 \%, 26.8 \%$ and $48.3 \%$ stated visual, auditory and kinesthetic respectively. In this case, they mostly prefer kinesthetic style.

The fifth opinion was "I tend to say I see what you mean, I hear what you are saying, or I know how you feel". In this opinion, $12.3 \%, 20.1 \%$ and $12.8 \%$ boys stated visual, auditory and kinesthetic respectively. Similarly, $13.1 \%, 25.3 \%$ and $16.4 \%$ girls stated visual, auditory and kinesthetic respectively. In total, $25.3 \%, 45.4 \%$ and $29.2 \%$ stated visual, auditory and kinesthetic respectively. In such case, students prefer auditory style of learning. The sixth opinion was "Complaining about faulty goods I tend to write a letter, phone or go back to the store/send the faulty item to the head office". In this opinion, $10.3 \%, 11.7 \%$ and $23.1 \%$ boys stated visual, auditory and kinesthetic respectively. Similarly, $14.9 \%, 14.7 \%$ and $25.3 \%$ girls stated visual, auditory and kinesthetic respectively. In total, $25.3 \%, 26.4 \%$ and $48.4 \%$ stated visual, auditory and kinesthetic respectively. In such case, students prefer kinesthetic style of learning.

The seventh opinion was "I prefer these leisure activities in museums/galleries, music/conversation or physical activities/making things". In this opinion, $14.2 \%, 8.4 \%$ and $22.3 \%$ boys stated visual, auditory and kinesthetic respectively. Similarly, 22.3\%, $7.9 \%$ and $24.8 \%$ girls stated visual, auditory and kinesthetic respectively. In total, 36.5\%, 16.3\% and $47.1 \%$ stated visual, auditory and kinesthetic respectively. In such case, majority students prefer kinesthetic style of learning. The eighth opinion was "When shopping, generally I tend to look \& decide, discuss with shop staff or try on/handle/test". In this opinion, $5.2 \%, 20.8 \%$ and $18.9 \%$ boys stated visual, auditory and kinesthetic respectively. Similarly, $10.7 \%, 27.3 \%$ and $17.2 \%$ girls stated visual, auditory and kinesthetic respectively. In total, $15.8 \%, 48.1 \%$ and $36.1 \%$ stated visual, auditory and kinesthetic respectively. In such case, majority students prefer auditory style of learning.

The ninth opinion was "Choosing a holiday, I read the brochures, listen to recommendations or imagine the experience". In this opinion, $23.0 \%, 6.5 \%$ and $15.1 \%$ boys stated visual, auditory and kinesthetic respectively. Similarly, 29.0\%, 8.5\% and $17.9 \%$ girls stated visual, auditory and kinesthetic respectively. In total, 52.0\%, $15.1 \%$ and $33.0 \%$ stated visual, auditory and kinesthetic respectively. In such case, majority students prefer visual style of learning. The tenth opinion was "Choosing a new car, I read the reviews, discuss with friend or test-drive what you fancy". In this opinion, $23.1 \%, 10.1 \%$ and $12.4 \%$ boys stated visual, auditory and kinesthetic respectively. Similarly, 27.0\%, $15.8 \%$ and $11.5 \%$ girls stated visual, auditory and kinesthetic respectively. In total, 50.1\%, 25.9\% and 23.9\% stated visual, auditory and kinesthetic respectively. In such case, majority students prefer visual style of learning.

The eleventh opinion was "Learning a new skill, I watch what the teacher is doing, I talk through with the teacher exactly what I am supposed to do or I like to give it a try and work it out as I go along by doing it". In this opinion, $28.1 \%, 13.1 \%$ and $3.8 \%$ boys stated visual, auditory 
and kinesthetic respectively. Similarly, $28.1 \%, 22.7 \%$ and $4.1 \%$ girls stated visual, auditory and kinesthetic respectively. In total, $56.3 \%, 35.8 \%$ and $7.9 \%$ stated visual, auditory and kinesthetic respectively. In such case, majority students prefer visual style of learning. The twelfth opinion was "Choosing from restaurant menu, I imagine what the food will look like, I talk through the options in my head or I imagine what the food will test like". In this opinion, 13.2\%, 11.8\% and $19.8 \%$ boys stated visual, auditory and kinesthetic respectively. Similarly, 17.3\%, 14.6\% and $23.4 \%$ girls stated visual, auditory and kinesthetic respectively. In total, 30.5\%, 26.4\% and $43.1 \%$ stated visual, auditory and kinesthetic respectively. In such case, majority students prefer kinesthetic style of learning.

The thirteenth opinion was "When listening to a band, I sing along to the lyrics (in my head or loud!), I listen to the lyrics and the beats or I move in time with the music." In this opinion, 9.9\%, 31.8\% and 3.3\% boys stated visual, auditory and kinesthetic respectively. Similarly, $11.1 \%, 41.6 \%$ and $1.6 \%$ girls stated visual, auditory and kinesthetic respectively. In total, $21.6 \%, 73.4 \%$ and $4.9 \%$ stated visual, auditory and kinesthetic respectively. In such case, majority students prefer auditory style of learning. The fourteenth opinion was "When concentrating, I focus on the words or pictures in front of me, discuss the problem and possible solutions in my head or move around a lot, fiddle with pens and pencils and touch unrelated things." In this opinion, $19.6 \%, 22.9 \%$ and $2.8 \%$ boys stated visual, auditory and kinesthetic respectively. Similarly, $22.4 \%, 30.7 \%$ and $1.7 \%$ girls stated visual, auditory and kinesthetic respectively. In total, $42.0 \%, 53.6 \%$ and $4.4 \%$ stated visual, auditory and kinesthetic respectively. In such case, majority students prefer auditory style of learning.

The fifteenth opinion was "I remember things best by writing notes or keeping printed details, saying them aloud/ repeating words and key points in my head or doing and practicing the activity/imagining it being." In this opinion, $12.7 \%, 9.6 \%$ and $22.9 \%$ boys stated visual, auditory and kinesthetic respectively. Similarly, $19.0 \%, 8.3 \%$ and $27.5 \%$ girls stated visual, auditory and kinesthetic respectively. In total, $31.7 \%, 17.9 \%$ and $50.4 \%$ stated visual, auditory and kinesthetic respectively. In such case, majority students prefer kinesthetic style of learning. The sixteenth opinion was "My first memory is of looking at something, being spoken to or doing something." In this opinion, $14.0 \%, 10.1 \%$ and $20.2 \%$ boys stated visual, auditory and kinesthetic respectively. Similarly, 22.1\%, $8.4 \%$ and $25.2 \%$ girls stated visual, auditory and kinesthetic respectively. In total, $36.1 \%, 18.5 \%$ and $45.4 \%$ stated visual, auditory and kinesthetic respectively. In such case, majority students prefer kinesthetic style of learning.

The seventeenth opinion was "When anxious, I visualize the worst-case scenarios, talk over in my head what worries me most or can't sit still, fiddle and move around constantly." In this opinion, $18.7 \%, 20.1 \%$ and $5.5 \%$ boys stated visual, auditory and kinesthetic respectively. Similarly, $28.1 \%, 20.9 \%$ and $6.6 \%$ girls stated visual, auditory and kinesthetic respectively. In total, $46.8 \%, 41.0 \%$ and $12.1 \%$ stated visual, auditory and kinesthetic respectively. In such case, majority students prefer visual style of learning. The eighteenth opinion was "I feel especially connected to others because of how they look, what they say to me or how they make me feel." In this opinion, $4.7 \%, 11.1 \%$ and $29.6 \%$ boys stated visual, auditory and kinesthetic respectively. 
Similarly, $7.2 \%, 10.5 \%$ and $36.8 \%$ girls stated visual, auditory and kinesthetic respectively. In total, $11.9 \%, 21.6 \%$ and $66.5 \%$ stated visual, auditory and kinesthetic respectively. In such case, majority students prefer kinesthetic style of learning.

The nineteenth opinion was "I revise for an exam; I write lots of revision notes (using lots of colors), I talk over my notes, to myself/to other people or imagine making the movement or creating the formula." In this opinion, $17.8 \%, 18.4 \%$ and $7.9 \%$ boys stated visual, auditory and kinesthetic respectively. Similarly, 22.6\%, $24.9 \%$ and $8.5 \%$ girls stated visual, auditory and kinesthetic respectively. In total, $40.4 \%, 43.2 \%$ and $16.4 \%$ stated visual, auditory and kinesthetic respectively. In such case, majority students prefer auditory style of learning. The twentieth opinion was "when explaining something to someone, I tend to show them what I mean, explain to them in different ways until they understand or encourage them to try and talk them through the idea as they try." In this opinion, $9.8 \%, 21.0 \%$ and $13.9 \%$ boys stated visual, auditory and kinesthetic respectively. Similarly, $13.4 \%, 24.3 \%$ and $17.5 \%$ girls stated visual, auditory and kinesthetic respectively. In total, $23.2 \%, 45.4 \%$ and $31.4 \%$ stated visual, auditory and kinesthetic respectively. In such case, majority students prefer auditory style of learning.

The twenty-first opinion was "my main interests are photography/watching films/peoplewatching, listening to music/listening to the radio/ talking to friends or physical/sports activities/fine wines, fine foods/dancing." In this opinion, $8.5 \%, 32.2 \%$ and $4.1 \%$ boys stated visual, auditory and kinesthetic respectively. Similarly, $9.1 \%, 42.7 \%$ and $3.3 \%$ girls stated visual, auditory and kinesthetic respectively. In total, $17.6 \%, 74.9 \%$ and $7.4 \%$ stated visual, auditory and kinesthetic respectively. In such case, majority students prefer auditory style of learning. The twenty-second opinion was "Most of my free time is spent watching television, talking to friends or doing physical activity/making things." In this opinion, $6.4 \%, 14.5 \%$ and $23.7 \%$ boys stated visual, auditory and kinesthetic respectively. Similarly, $10.3 \%, 17.0 \%$ and $28.1 \%$ girls stated visual, auditory and kinesthetic respectively. In total, $16.7 \%, 31.5 \%$ and $51.8 \%$ stated visual, auditory and kinesthetic respectively. In such case, majority students prefer kinesthetic style of learning.

The twenty-third opinion was "when I first contact a new person, I arrange a face to face meeting, I talk to them on the telephone or I try to get together to share an activity" In this opinion, $20.8 \%, 10.4 \%$ and $14.1 \%$ boys stated visual, auditory and kinesthetic respectively. Similarly, $23.7 \%, 18.3 \%$ and $12.7 \%$ girls stated visual, auditory and kinesthetic respectively. In total, $44.5 \%, 28.7 \%$ and $26.8 \%$ stated visual, auditory and kinesthetic respectively. In such case, majority students prefer visual style of learning. The twenty-fourth opinion was "I first notice how people, look and dress, sound and speak or stand and move." In this opinion, 12.1\%, 23.9\% and $8.4 \%$ boys stated visual, auditory and kinesthetic respectively. Similarly, $13.8 \%, 30.0 \%$ and $11.5 \%$ girls stated visual, auditory and kinesthetic respectively. In total, 25.8\%, 54.2\% and $19.9 \%$ stated visual, auditory and kinesthetic respectively. In such case, majority students prefer auditory style of learning.

The twenty-fifth opinion was "I am very angry, I keep replaying in my mind what it is that has upset, I shout lots and tell people how I feel or I stomp about, slam doors and throw 
things." In this opinion, $34.4 \%, 5.8 \%$ and $4.7 \%$ boys stated visual, auditory and kinesthetic respectively. Similarly, $46.7 \%, 6.1 \%$ and $2.2 \%$ girls stated visual, auditory and kinesthetic respectively. In total, $81.1 \%, 11.9 \%$ and $6.9 \%$ stated visual, auditory and kinesthetic respectively. In such case, majority students prefer visual style of learning. The twenty-sixth opinion was "I find it easiest to remember faces, names or things I have done." In this opinion, $10.2 \%, 20.2 \%$ and $14.4 \%$ boys stated visual, auditory and kinesthetic respectively. Similarly, $13.0 \%, 24.9 \%$ and $17.2 \%$ girls stated visual, auditory and kinesthetic respectively. In total, $23.3 \%, 45.2 \%$ and $31.6 \%$ stated visual, auditory and kinesthetic respectively. In such case, majority students prefer auditory style of learning.

The twenty-seventh opinion was "I think I can tell someone is lying because they avoid looking at you, their voice changes or the vibes I get from them." In this opinion, 11.7\%, 16.9\% and $16.9 \%$ boys stated visual, auditory and kinesthetic respectively. Similarly, $14.7 \%, 17.2 \%$ and $22.5 \%$ girls stated visual, auditory and kinesthetic respectively. In total, 26.4\%, 34.2\% and $39.4 \%$ stated visual, auditory and kinesthetic respectively. In such case, majority students prefer kinesthetic style of learning. The twenty-eighth opinion was "when I am meeting with an old friend, I say "it's great to see you!", I say " it's great to hear your voice!" or I give them a hug/a handshake." In this opinion, $21.0 \%, 4.6 \%$ and $19.3 \%$ boys stated visual, auditory and kinesthetic respectively. Similarly, $37.3 \%, 4.4 \%$ and $13.4 \%$ girls stated visual, auditory and kinesthetic respectively. In total, $58.3 \%, 9.0 \%$ and $32.7 \%$ stated visual, auditory and kinesthetic respectively. In such case, majority students prefer visual style of learning.

Various previous researchers have conducted the study on gender differences in learning styles. Because of family orientation, cultural orientation and school environment, male and female can learn the same thing from different ways. Wehrwein, Lujan, \& DiCarlo (2007) conducted research on "Gender differences in learning style adopting the model of visual (V), auditory (A), read-write) and kinesthetic (K) which found that $54.2 \%$ of females and only $12.5 \%$ of males preferred a single mode of information presentation. Among the female students, $4.2 \%$ of the students preferred V whereas no students preferred A. Similarly, 16.7\% of the students preferred printed words $(\mathrm{R})$, and $33.3 \%$ of the students preferred using all their senses $(\mathrm{K})$. In contrast, male students were preferring A, R, or K, respectively, while no single male students preferred V. Furthermore, $45.8 \%$ of female and $87.5 \%$ of male respondents preferred multiple modes of presentation. In summary, a majority of male students preferred multimodal instruction, specifically, four modes (VARK), whereas a majority of female students preferred single mode instruction with a preference toward K (Wehrwein, Lujan, \& DiCarlo, 2007, p. 153). The previous study concluded that male and female students have significantly different learning styles. It is the responsibility of the instructor to address this diversity of learning styles and develop appropriate learning approaches. The finding of previous studies as mentioned above is found different with the finding of this present study because the present study has found that there is no significant difference in male and female students regarding their learning style (VAK).

\section{Sex wise types of learning style}


The study analyzed the total value of visual, auditory, kinesthetic learning style of male and female students to find out their relationship. Table 2 shows the SPSS output of independent sample t-test for gender difference in learning styles.

Table2: Sex wise types of learning style.

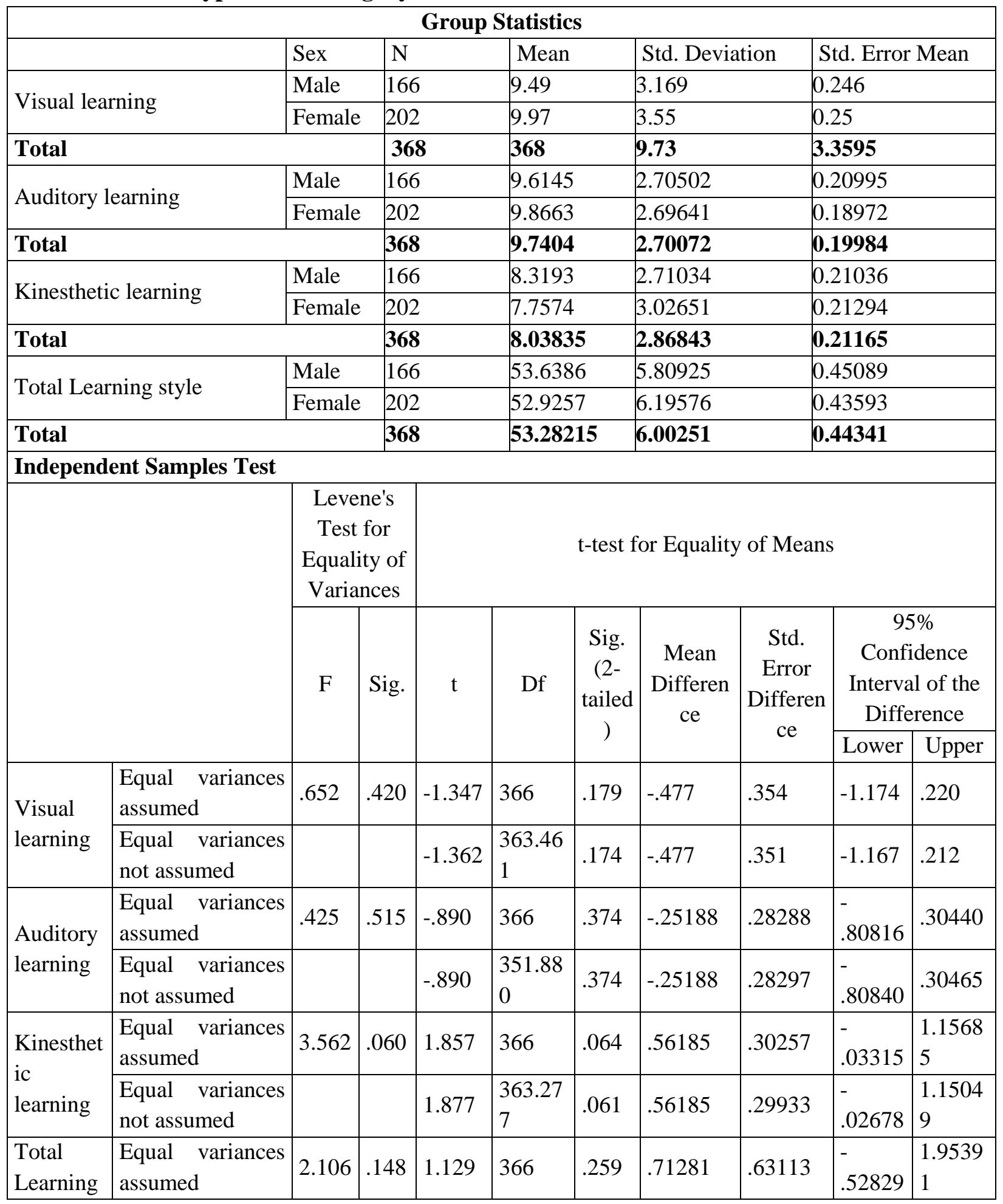




\begin{tabular}{|l|l|l|l|l|l|l|l|l|l|l|}
\hline style & $\begin{array}{l}\text { Equal variances } \\
\text { not assumed }\end{array}$ & & 1.137 & $\begin{array}{l}359.66 \\
5\end{array}$ & .256 & .71281 & .62716 & $\begin{array}{l}- \\
.52056\end{array}$ & $\begin{array}{l}1.9461 \\
8\end{array}$ \\
\hline
\end{tabular}

Source: Field Survey, 2016

For observation of visual learning style, the significant value of Levene's Test for equality of variance is 0.420 , which is more than 0.05 ; it means that the equal variances are assumed. Therefore, we have to use 0.179 as significance 2-tailed to determine null hypothesis either reject or accept. Since the value is more than 0.05 , then null hypothesis is accepted. It means that there is no difference in learning style (visual) between boys and girls. For observation of auditory learning style, the significant value of Levene's Test for equality of variance is 0.515 , which is more than 0.05; it means that the equal variances are assumed. Therefore, we have to use 0.374 as significance 2 -tailed to determine null hypothesis either reject or accept. Since the value is more than 0.05 , then null hypothesis is accepted. It means that there is no difference in learning style (auditory) between boys and girls. For observation of kinesthetic learning style, the significant value of Levene's Test for equality of variance is 0.060 , which is more than 0.05; it means that the equal variances are assumed. Therefore, we have to use 0.064 as significance 2 -tailed to determine null hypothesis either reject or accept. Since the value is more than 0.05 , then null hypothesis is accepted. It means that there is no difference in learning style (kinesthetic) between boys and girls. While observing total learning style, the significant value of Levene's Test for equality of variance is 0.148 , which is more than 0.05 ; it means that the equal variances are assumed. Therefore, we have to use 0.259 as significance 2tailed to determine null hypothesis either reject or accept. Since the value is more than 0.05 , then null hypothesis is accepted. It means that there is no difference in total learning style between boys and girls.

Some of the previous studies have found the significant difference in learning style of male and females whereas the current study found the no difference in male and female students regarding their learning style. A study conducted by Yildirim and Sevinc (2010) among Iranian undergraduate English as Foreign Language (EFL) learners' choice of vocabulary learning strategies found that there was no statistically significant difference between the vocabulary strategy preferences or learning styles between male and females.

On the contrary, there are some studies, which reported that there was gender difference in learning styles (Aripin \& Mahmood, 2008; Scott, 2010; Kember \& Wong, 1995). For instance, Aripin and Mahmood (2008) assessed the learning style preferences among 540 ESL students from a private university through the Perceptual Learning Style Preference Questionnaire (PLSPQ) by Joy Reid. It was reported that there was a significant difference between male and female students regarding their learning styles. Meanwhile, Kember and Wong reported that the male group prefers kinesthetic learning style while the female group prefers visual learning style (Middleton, Ricks, Wright, \& Grant, 2013; Choudhary, Dullo, \& Tandon, 2011). On the basis of previous findings, some researchers have generalized that gender differences play a significant role in determining the learning style (Rezaeinejada, Azizifara, \& Gowharya, 2015; WorleyDavis, 2012). 
The present study found the significantly different result than the many previous studies. More previous studies have found the significant difference in learning style of male and female whereas very few literatures shows the similar type of learning style in male and female. The similarity and variation in result may be affected by the geographical setting, school environment, and grade and socio-culture orientation of students. In the Nepalese context, this is the new knowledge that there is no difference in learning of male and female which indicates the equality; no gender based discrimination and stratification in educational institutions.

\section{CONCLUSIONS}

The study has measured the 28 parameter of learning style developed by Neil Fleming. The learning parameter has covered the three types of learning style: Visual, Auditory, and Kinesthetic. The study found that out of 28 questions, there is significant association between boy and girls student in only 3 questions. In total, there is no significant difference between boy and girl students regarding their learning style. It shows that learning style is not affected being boys and girls of Nepalese students of public and private school. It can be concluded that the findings has challenged the socio-cultural norms towards the gender relation. In Nepalese culture, girls are taken as a less creative and effective than male so there is work division in boys and girls. From the educational perspective, parents hesitate to send their daughter far from the home whereas son is known as a brave person so he can be send anywhere for education and employment. The study indicated the similar types of learning interest and style of boys and girls so it can be assumed about the similar types of achievement in future work. If daughters were to get better learning opportunity, they could give better result and can significantly contribute in nation building. The future research can be done on comparative study on public and private school's student regarding their learning style.

\section{REFERENCES}

Aripin, R., \& Mahmood, Z. (2008). Students' learning styles and academic performance. Paper presented at the 22nd Annual SAS Malaysia Forum, Kuala.

Bailey, P., Onwuegbuzie, A. J., \& E., D. C. (2000). Using Learning Style to Predict Foreign Language Achievement at the College Level. System , 28, 115-133.

Busato, V. V., Prins, F. J., Elshout, J. J., \& C., H. (2000). Intellectual Ability, Learning Style, Personality, Achievement Motivation and Academic Success of Psychology Students in Higher Education. Personality and Individual Differences , 29, 1057-1068.

Chou, H., \& Wang, T. (2000). The Influence Learning Style and Training Method on SelfEfficacy and Learning Performance in WWW Homepage Design Training. International Journal of Information Management, 20 (4), 455-472. 
Choudhary, R., Dullo, P., \& Tandon, R. V. (2011). Gender differences in learning style preferences of first year Medical students. Pak J Physiol, 7(2), 42-45. Pak J Physiol , 7 (2), 42-45.

Claxton, C., \& Ralston, Y. (1978). Learning Styles: Their impact on teaching and administration. Washington, DC: American Association for the study of higher Education.

Clenton, J. (2015). Learning styles and the Japanese. Retrieved April 30, 2016, from World Web Site: http://www.sussex.ac.uk/langc/skills/LearningStylesJapanese.pdf

Fox, J., \& Batholomae, S. (1999). Student Learning Style and Educational Outcomes: Evidence from a Family Financial Management Corse. Financial Services Review , 8 (3), 235-251.

Grenfell, M., \& Harris, V. (1999). Modern languages and learning strategies: In theory and practice. In C. Grifths, Lessons from Good Language Learners. Cambridge: Cambridge University Press.

Grifths, C. (2008). Lessons from Good Language Learners. Cambridge: Cambridge University Press.

Hsu, C. H. (1999). Learning Styles of Hospitality Students: Nature or Nurture? Hospitality Management , 18 (2), 17-30.

Keefe, J. W. (1979). Student learning styles: Diagnosing and prescribing programs. In J. W. Keefe, Learning style: An overview (pp. 1-17). Reston, VA: National Association of Secondary School Principals.

Kember, D. J., \& Wong, E. T. (1995). Learning approaches, study time and academic performance. Higher Education. 29 (3), 329-333.

Kolb, D. A. (1999). Learning Style Inventory. Boston: Hay/McBer.

Middleton, K., Ricks, E., Wright, P., \& Grant, S. (2013). Middleton, K., Ricks, E., Wright, P., \& Grant, S. (2013). Examining the relationship between learning style preferences and attitudes toward Mathematics among students in higher education. Institute for Learning Styles Journal , 1 (1), 1-15.

Reid, J. M. (1987). The learning style preferences of ESL students. TESOL Quarterly , 21 (1), 87-111.

Rezaeinejada, M., Azizifara, A., \& Gowharya, H. (2015). The study of learning styles and its relationship with educational achievement among Iranian high school students. Procedia Social and Behavioral Sciences , 199, 218-224.

Rourke, B., Ahmed, S., Collins, D., Hayman-Abello, W., \& Warriner, B. (2002). Child clinical/pediatric neuropsychology: some recent advances. Clinical Psychology , 53, 309339.

Sadler-Smith, E. (2001). The Relationship Between Learning Style and Cognitive Style. Personality and Individual Differences , 30, 609-616.

Scott, C. e. (2010). The enduring appeal of "learning styles". Australian Journal of Education. 54 (1), 5-17. 
Wehrwein, E. A., Lujan, H. L., \& DiCarlo, S. E. (2007). Gender differences in learning style preferences among undergraduate physiology students. Journal of Applied Physiology, 31 (2), 153-157.

Worley-Davis, L. (2012). A comparison of learning styles and academic performance of students enrolled in introductory poultry science courses in bachelor of science and associates of applied science program.

Yildirim, O. A., \& Sevinc, L. (2010). Relationships between teachers' perceived leadership style, students' learning style, and academic achievement: A study on high school students. 28 (1), 73-81. 